\title{
Free Will From the Neurophilosophical Perspective
}

\section{Nada Gligorov}

To cite this article: Nada Gligorov (2010) Free Will From the Neurophilosophical Perspective, AJOB Neuroscience, 1:1, 49-51, DOI: 10.1080/21507740903504475

To link to this article: http://dx.doi.org/10.1080/21507740903504475

$$
\text { 曲 Published online: } 17 \text { Feb } 2010 .
$$

Submit your article to this journal

$$
\text { LII Article views: } 47
$$

Q View related articles $₫$

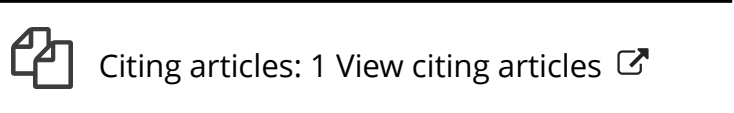


et al. (2010) deontological justification of HAT who would have access to treatment and who would pay. Their argument for the "right to injectable heroin" suggests that they would advocate more liberal use of HAT among opioid drug users. But providing HAT as a first-line treatment to anyone seeking treatment for heroin dependence would further reduce the numbers of individuals who could be treated. It would also potentially expose individuals to the harms arising from regular injecting heroin use who might have otherwise responded to standard forms of treatment.

Lack of access to treatment for opioid dependence is already a major problem in most developed countries. Patients can wait several months to get into OST, even in countries with well-established programs (e.g., Europe, Australia, and Canada). The provision of HAT to $5-10 \%$ of addicted heroin users would significantly reduce the ability of treatment systems to provide oral OST to the vast majority of patients (Lintzeris 2009). A case therefore needs to be made that it is ethically acceptable to use limited health care resources to provide a more expensive treatment for a minority of patients at the expense of providing cheaper treatment that benefits many more.

We believe that the inability to provide safe and effective treatment to all those in need is a more significant challenge than a putative right to injectable heroin treatment programs. A complete analysis of the ethical acceptability of HAT therefore needs to go beyond the right of individuals to access it, to consider the impact that its provision may have on access to effective treatment for the majority of opioid-dependent individuals.

\section{REFERENCES}

Buchman, D., W. Skinner, and J. Illes. 2010. Negotiating the relationship between addiction, ethics, and brain science. AJOB Neuroscience 1(1): 36-45.
Carter, A., and W. Hall. The rights of individuals treated for addiction. In Mental health and human rights, eds. D. Dudley, D. Silove, and F. Gale. London: Oxford University Press. In press.

Dijkgraaf, M. G., B. P. van der Zanden, C. A. de Borgie, et al. 2005. Cost utility analysis of co-prescribed heroin compared with methadone maintenance treatment in heroin addicts in two randomised trials. British Medical Journal 330(7503): 1297.

Haasen, C., U. Verthein, P. Degkwitz, et al. 2007. Heroin-assisted treatment for opioid dependence: Randomised controlled trial. British Journal of Psychiatry 191(1): 55-62.

Lintzeris, N. 2009. Prescription of heroin for the management of heroin dependence: Current status. CNS Drugs 23(6): 463-476.

Lintzeris, N., J. Strang, N. Metrebian, et al. 2006. Methodology for the Randomised Injecting Opioid Treatment Trial (RIOTT): Evaluating injectable methadone and injectable heroin treatment versus optimised oral methadone treatment in the UK. Harm Reduction Journal 3(1): 28-40.

Mattick, R. P., C. Breen, J. Kimber, and M. Davoli. 2009. Methadone maintenance therapy versus no opioid replacement therapy for opioid dependence. Cochrane Database of Systematic Reviews 3: CD002209.

Oviedo-Joekes, E., B. Nosyk, D. Marsh, et al. 2009. Scientific and political challenges in North America's first randomized controlled trial of heroin-assisted treatment for severe heroin addiction: Rationale and design of the NAOMI study. Clinical Trials 6(3): 261.

Perneger, T. V., F. Giner, M. del Rio, and A. Mino. 1998. Randomised trial of heroin maintenance programme for addicts who fail in conventional drug treatments. British Medical Journal 317(7150): 1318.

Strang, J., N. Lintzeris, N. Metrebian, and D. Zador. 2009. RIOTT: Findings of the RCT of Injectable Opioid Treatment Trial (Paper No. 283). The Australian Professional Society of Alcohol and other Drugs Conference: "Living on the Edge", 1-4 November, Darwin, Australia. Drug and Alcohol Review 28(s1): a61.

\title{
Free Will From the Neurophilosophical Perspective
}

\author{
Nada Gligorov, Mount Sinai School of Medicine
}

In explaining human psychology and behavior, a dichotomy is often established between scientific explanations in neuroscience or neurology, and explanations that rely on psychological or social factors. Buchman and colleagues (2010) appeal to this dichotomy between what they call the neu- rophilosophical perspective and the psychosocial perspective. On the one hand, we have a reductivist and determinist view, which explains human behavior in general and addictive behavior in particular, by offering an approach where human psychology can be reduced to the workings

Address correspondence to Nada Gligorov, Mount Sinai School of Medicine, Medical Education, One Gustave Levy Place, Box 1108, New York, NY 10029, USA. E-mail: nada.gligorov@mssm.edu 
of the brain. These approaches are often taken to undermine the claim that human behavior is guided by free will. On the other hand, psychological and social explanations that emphasize the interaction of humans with their environment are seen as preserving free will, in part because they are not seen as reductivist. I argue that the dichotomy established between the two approaches is a false one and rests on misconceptions about the two types of proposed explanations of addiction.

The neurophilosophical perspective is considered reductivist because it seeks to explain psychological phenomena by reducing it to brain processes. The neurophilosophical perspective is thought to be determinist as well. If psychological phenomena can be explained in terms of brain processes, then our psychological states are nothing but the physical events in the brain, which can be subsumed under the workings of determinist scientific laws. Determinism has a large impact on moral theory because it is seen as undermining claims of free will and consequently claims of moral responsibility. Given that a precondition for free will is that a person could have done otherwise, if a person's behavior is entirely determined by her brain physiology, we can no more blame someone for what they do than we can blame that person for being short. We see this reflected in explanations of addiction. If addiction is approached from the neurological perspective and deemed a medical condition, a "brain disease," it makes it unjustified to blame those suffering from this illness for not being able to curb their drug use. We see addicts as merely victims of their medical condition. It is worth noting that determinism, as described earlier, makes a very general claim, which is not limited to addiction, that all of human psychology and behavior that can be explained from the neurophilosophical perspective is determined by scientific laws.

There are, however, alternative interpretations to the neurophilosophical perspective. For one, the current state of neuroscience has not yielded direct support for determinism.

\footnotetext{
The picture that neuroscience has yielded so far is one of mechanisms infused with indeterministic or stochastic (random or probabilistic) processes. Whether or not a neuron will fire, what pattern of action potentials it generates, or how many synaptic vesicles are released have all been characterized as stochastic phenomena in our current best models. (Roskies 2006, 420)
}

It is unclear whether the indeterminism suggested by the current best models is a feature of the brain or a failure of those models to capture its deterministic nature. Either way, the apparent indeterminism at the level of neurons can be compatible with the assumption of determinism at a more fundamental physical level (Roskies 2006, 420-423). As a consequence, to adopt the neurological perspective on addiction does not commit us to determinism, and does not entail giving up on free will and responsibility. A person could be characterized as having a medical condition of addiction and still be responsible for his or her actions and be influential in his or her recovery process.
That said, even if the time comes when neuroscience starts yielding determinist processes, there are compatibilist views that could still accommodate free will for morality and determinism in science. One could appeal to a higher-order account of free will, such as Harry Frankfurt's (Frankfurt 1971). On this view a person may have two kinds of desires, first-order desires and second-order desires. First-order desires are caused by compelling external stimuli, such as drugs or food, while second-order desires are endogenous and may conflict with first-order desires. The second-order desire for an addict would likely be to no longer want to use drugs. Free will is then expressed when a person acts in terms of his or her second-order desires. An addict might not be able to influence her first-order desire to use drugs, but her second-order desires not to use are internally motivated and are the locus of free will and autonomy. As a result, we may hold people responsible for not following their second-order desires. On Frankfurt's view, and that of others, ${ }^{1}$ free will is compatible with a neurophilosophical perspective on addiction.

Returning to the psychosocial systems approach suggested by Buchman and colleagues, we should mention that those approaches are not immune to either reduction or determinism. If we take the explanation of human psychology and behavior to have many levels, we could differentiate a level of social explanation, where social phenomena are established and group interactions are used to explain or predict the behavior of individuals. Buchman and colleagues cited research that shows that the social environment can increase cravings and may increase drug consumption. We could also identify psychological explanations, which seek to identify psychological laws or mechanisms that are then used to explain or predict individual psychology. There could be emotional factors or other predispositions, which could increase a person's likelihood to become and addict. Finally, we can identify the neuroscientific perspective, which aims to identify brain processes involved in disease and those taken to underlie various cognitive and emotional processes.

The neurophilosophical perspective has been described as assuming a reduction of addiction to brain process, and the psychosocial systems approach was depicted as preferable because it provides a non-reductive view that preserves autonomy. Reduction, however, may apply to any level of explanation cited earlier. ${ }^{2}$ The levels of explanation already described constitute a collapsible hierarchy where higher level explanations may be reduced by theories at the lower physical level. ${ }^{3}$ The social model of addiction is in principle reducible to the psychological level of explanation, whereby social phenomena said to influence addiction could be reduced to consequences of individual psychology. Cultures,

1. For a contemporary version of compatibilism see Dennett (2003). 2. For a classical view on reduction see, Nagel (1961).

3 . This type of reduction would be motivated by the theoretical unification of theories where the truth of one theory entails the truth of other theories. For more on the view of scientific unification, see Kukla (1998, chap.4). 
peers, and families may be characterized as nothing but the individuals constitutive of those groups. We then have a reduction of the social level of explanation to the psychological level of explanation. The psychological level of explanation can be in turn reduced to the neuroscientific framework, resulting in the identification of psychological phenomena with brain states. And even the neuroscientific level of explanation may be subsumed by a more fundamental physical theory.

Finally, determinism could be a feature of a psychosocial explanation in two ways. Assuming that the psychosocial level is reducible to the neuroscientific explanation of human behavior, then determinism will be a feature of the psychosocial systems model insofar as it is a feature of neuroscience. Opting for a higher level explanation of addiction would not eliminate the threat to free will, and preserving autonomy would still be a problem for any explanation of addiction. Determinism, however, could be a feature at any level of explanation, even without reduction. Most theories about human behavior seek to provide generalized rules, or laws, for the explanation and prediction of individual psychology and conduct. It is precisely this law-like feature of scientific explanation, not the domain of the theory, that is a threat to autonomy. Any explanation of addiction, whether social or psychological, that seeks to establish general rules for individual behavior could have determinism as a feature.

The upshot of this paper is that the psychosocial model may not escape the traps of reduction or determinism; both those features could reemerge on the proposed account. In addition, the neurophilosophical perspective does not have to be a threat to free will. Determinism does not as of yet seem to be a feature of neuroscientific explanations. Even if it were, however, the compatibilist perspective on free will could countenance determinism in brain science and still be able to attribute autonomy to those suffering from addiction. In general, it is not necessary to construe the neurophilosophical perspectives as entailing the denial of free will. There is not a deep cleft between neurological explanations of addiction and those that focus more on social and psychological perspectives. All those approaches should be seen as continuous; they share similar pitfalls and should be used for their best features to explain and treat addiction.

\section{REFERENCES}

Buchman, D. Z., W. Skinner, and J. Illes. 2010. Negotiating the relationship between addiction, ethics, and brain science. AJOB Neuroscience 1(1): 36-45.

Dennett, D. 2003. Freedom Evolves. London: Penguin Books.

Frankfurt, H. 1971. Freedom of the will and the concept of a person. Journal of Philosophy 68: 5-20.

Kukla, A. 1998. Studies in Scientific Realism. New York: Oxford University Press.

Nagel, E. 1961. The Structure of Science. New York: Harcourt, Brace, and World.

Roskies, A. 2006. Neuroscientific challenges to free will and responsibility. Trends in Cognitive Science 10: 419-423.

\title{
What Does Integration Mean in a Biopsychosocial Systems Approach in Addiction Neuroethics?
}

\author{
Craig L. Fry, Murdoch Children's Research Institute and University of Melbourne
}

Buchman, Skinner, and Illes (2010) propose a biopsychosocial systems model as an essential interdisciplinary and integrated approach to understanding and responding to drug addiction. In principle, the notion of interdisciplinary work toward the integration of "biological data and psycho-social, narrative, family information, and clini- cal phenomenology" seems worthwhile (Buchman, Skinner, and Illes 2010). But what exactly is integration, and how can it be achieved in addiction neuroethics in practice?

For many practitioners and other professionals working in the diverse drug and alcohol field, striving to develop multidisciplinary approaches to research, treatment,

Acknowledgments: CF is supported by an NHMRC Australian Public Health Training Fellowship (519556), ARC Discovery Grant (1094144), the Murdoch Children's Research Institute (Children's Bioethics Centre), and the University of Melbourne (Centre for Applied Philosophy \& Public Ethics).

Address correspondence to Craig L. Fry, Children's Bioethics Centre, Murdoch Childrens Research Institute and Centre for Applied Philosophy \& Public Ethics, University of Melbourne, PO Box 911, Parkville, Victoria 3052, Australia. E-mail: craig.fry@mcri.edu.au 